EstAg 30 (1995) 415-436

\title{
Beato Anselmo Polanco Fontecha (1881-1939)
}

\author{
Vida y Escritos
}

\section{VIDA}

El día $1^{\circ}$ de octubre de 1995 el Papa Juan Pablo II declaraba al venerable Anselmo Polanco Fontecha Beato: bienaventurado, digno de veneración por haber sido testigo de Cristo, mártir, con el derramamiento de su sangre ${ }^{1}$. Fue el paso previo para llegar al más alto grado de distinción y exaltación que la Iglesia concede, después de muertos, a quienes han sufrido el martirio o han cultivado de una manera más eminente, esto es, en el llamado grado heroico, las virtudes cristianas: la canonización, inscripción en el canon o catálogo de los santos. Estas declaraciones no implican, ni suponen, que los beatificados o canonizados hayan ejercitado las virtudes o sufrido el martirio en un grado superior a otros cristianos que no han logrado ese reconocimiento. Para que se les reconozca, se hace casi indispensable que haya algún «mecenas» o entusiasta que presente y promueva la respectiva causa ante la Congregación pontificia para las Causas de los Santos. Aunque no están inscritos todos los que son modelos relevantes, sí lo son todos los que están. Lo son, con amplísimo margen de edificación y de prestigio, el P. Anselmo Polanco y su Vicario General Felipe Ripoll ${ }^{2}$.

1. Sobre el desarrollo del instituto de la beatificación y canonización, cf. Balbino RANO, O.S.A., La manera de hacer un santo. Consideraciones en torno a la beatificación del obispo Anselmo Polanco, O.S.A., en Religión y Cultura 42 (Madrid 1995), pp. 305-319.

2. Sobre su vida y martirio, cf. Amador del FUEYO, O.S.A., Héroes de la epopeya. El obispo de Teruel, Madrid 1941; Luis CAMBLOR, O.S.A., El Obispo-Mártir de Teruel, Madrid 1952; CONGREGACIÓN PARA LAS CAUSAS DE LOS SANTOS, Terulen. beat. seu declarat. Martyrii SS. Servi Dei Anselmi Polanco, Episcopi Terulen., O.S.A., et Philippi Ripoll, Sacerdotis..., positio super Martyrio, Roma [1963- ] 1992; Balbino RANO, O.S.A., Polanco Fontecha, Anselmo e Ripoll Morata, Philippo, martiri, en Bibliotheca Sanctorum, 1a append., Roma 1987, 1067-1069, con abundante bibliografía. Jerónimo BELTRÁN, Tras las huellas del P. Polanco, Teruel 1989; CON- 
El Beato Anselmo nació en Buenavista de Valdavia (Palencia) el 16 de abril de 1881. Fue bautizado el siguiente día 21. Hechos los primeros estudios en su pueblo natal, en 1892 pasa a la preceptoría existente en el vecino pueblo de Barriosuso a prepararse en los estudios adecuados para emprender la carrera sacerdotal. Con este fin ingresa en el real Colegio-Seminario Agustino de Valladolid en el mes de julio de 1897. En el mismo colegio completa los estudios medios y cursa los de la filosofía y el primer año de teología, hasta 1902. En el curso 1899-1900 tiene que interrumpir los estudios por motivo de enfermedad, ausentándose de Valladolid. Los superiores lo enviaron primero a la casa de los capellanes agustinos del Convento de Agustinas de vida contemplativa de Medina del Campo; después creyeron más conveniente para su recuperación enviarlo a casa de sus padres en Buenavista de Valdavia ${ }^{3}$. De nuevo en Valladolid, emite los votos solemnes el 3 de agosto de 1900.

Acabado el primer curso de teología, el 1 de septiembre de 1902 se traslada al Convento de Santa María de La Vid (Burgos) para cursar los otros tres cursos de teología. El 17 de diciembre de 1904, era ordenado sacerdote por el Obispo diocesano en Burgo de Osma (Soria). Acabados los estudios teológicos en junio de 1905, en 1906 fue destinado a Alemania con el fin de prepararse en la pedagogía y técnica de los centros de enseñanza de aquella nación para aplicarlos a los colegios de la Provincia del Santísimo Nombre de Jesús de Filipinas en España. Estuvo allí, sobre todo en Würzburg, poco más de un año. Los superiores repensaron y creyeron más conveniente dedicarlo a la formación de los jóvenes profesos agustinos 4 .

En octubre de 1909 era nombrado ayudante del Maestro de profesos de Valladolid y pasante, algo así como profesor auxiliar. En el capítulo celebrado en mayo de 1909 se le nombra Maestro de los mismos profesos. Este mismo año, hechos en Valladolid los exámenes exigidos, el Prior General Tomás Rodríguez lo declara el 1 de mayo Lector, título equivalente, con valor dentro de la Orden, al de un Licenciado.

GREGACIÓN PARA LAS CAUSAS DE LOS SANTOS, ... Summarium additum, Roma 1990; ID., Relatio et vota congressus peculiaris super martyrio die 22 martii an. 1994 habiti, Roma 1994; Teófilo APARICIO, O.S.A., Anselmo Polanco. Al servicio de Dios y de la Iglesia; Madrid 1995; Jerónimo BELTRÁN. Felipe Ripoll. Historia de una fidelidad, Madrid 1995; Joaquín GARCÍA ABAD, Dar la vida por amor. Anselmo Polanco, OSA., Obispo de Teruel. Felipe Ripoll, Presbitero de Teruel, Madrid 1995; Miguel PASTOR, O.S.A., El P. Anselmo Polanco modelo de religioso agustino al servicio de la Iglesia. Carta Circular, Madrid 1995.

3. Cf. A. del FUEYO, ob. cit., p. 35; constancia de haber hecho el primer curso de teología en Valladolid, en Colegio de PP. Agustinos. Regesta Studiorum Vallisoleti, Ms., en la Secretaría del Estudio Teológico Agustiniano, f. 1r., curso 1901-1902.

4. Cf. Gregorio de S. VELA., Ensayo de una biblioteca ibero-americana de la O.S.A., vol. VI, Madrid 1922, p. 334: el P. Vela acudió directamente a los escritores que vivían, para que le ofreciesen la biografía y bibliografía. 
En diciembre de 1913 se le traslada a La Vid de profesor de teología. Hechos en Madrid los exámenes previos, el mismo Prior General le hace Regente de estudios el 2 de noviembre de 1916. Finalmente el 26 de octubre de 1921 le fue concedido, sin necesidad de ningún examen, el título de Maestro en teología como coronación de su dedicación a los estudios eclesiásticos, título que, habiendo equivalido en otros tiempos dentro de la Orden Agustina al título universitario de Doctor, en este tiempo no pasaba de ser ya un simple título honorífico; razón suficiente para eliminarlo en 1968 de las Constituciones de la Orden.

En Septiembre de 1922 regresa a Valladolid por haber sido elegido en el Capítulo Provincial Prior de la Comunidad, cargo en el que fue confirmado para un trienio en el Capítulo de 1926. En 1924 había sido elegido para participar en la categoría de Discreto al Capítulo general de Roma de 1925. Le causó una satisfacción muy gozosa la elección de Prior General del eficiente P. Eustasio Esteban, miembro también de la Provincia del Santísimo Nombre de Jesús de Filipinas. En el siguiente Capítulo provincial de 1929 fue elegido Definidor (Consejero) de la Provincia. El Prior Provincial reelegido, P. Gaudencio Castrillo, creyó conveniente que la sede de la Provincia y, en consecuencia, la residencia del Prior Provincial y Consejo se mantuviesen, de acuerdo con la mente del capítulo, en Manila ${ }^{5}$. Por lo tanto, allí habría de residir el Definidor Anselmo Polanco. Así figura en los catálogos de la Provincia de 1929 y 1931 6. Sin embargo, tanto el Prior Provincial como los demás miembros del Consejo o Definitorio continuaron en España hasta la segunda mitad del año 1931. El Prior Provincial se embarcó para Filipinas, con el Definidor Felipe Landázaru y el Secretario Francisco Aymerich, en el mes de noviembre ${ }^{7}$. El P. Polanco había embarcado antes y ya se encontraba en Manila en el mes de octubre, después de haber estado algún tiempo en China ${ }^{8}$.

El P. Polanco continuó en España supervisando los últimos detalles de la edificación de la iglesia agustina vallisoletana, que se había reanudado durante su gobierno de Prior de la Comunidad; cuidando la redacción del proyecto de los Estatutos de la Provincia y dedicándose a otros quehaceres. El 12 de junio de 1930, fiesta de San Juan de Sahagún y XV Centenario de la

5. Cf. Capitulum provinciale augustinianae provinciae sanctissimi Nominis Insularum Philippinarum Vallisoleti celebratum an. D. 1929, Valladolid 1929, p. 16.

6. Cf. Nomenclátor de los religiosos agustinos de la Prov. del Smo. Nombre de Jesús de Filipinas. Diciembre 1929. Valladolid, 1929, p. 2. Nomenclátor... Año 1931, Bilbao 1931, p. 2.

7. Cf. Archivo Agustiniano 37 (1932) p. 143.

8. Cf. A. POLANCO, Carta desde Zaragoza, 27.IV.1931, a la Hna. Natividad de San José, del convento agustino de Sancti Spiritus de Valladolid; carta a la misma Hna. desde Manila, 30.X.1931. 
muerte de San Agustín, tuvo la satisfacción de participar en la consagración de la citada iglesia, de la que había sido principal promotor. Fue consagrante su admirador e hijo de confesión el Sr. Arzobispo de la Diócesis, D. Remigio Gandásegui. También participó en las celebraciones del triduo tenido con ese motivo los días 13-15 9. Quedó complacido. «Los actos del triduo-escribía a las agustinas de Medina del Campo- resultaron concurridísimos y solemnes sobre toda ponderación. Pidan al Señor que se le dé mucha gloria en el recién abierto templo».

También con motivo del XV Centenario de la muerte de San Agustín regresó a Italia en 1939 para representar a la Provincia de Filipinas, al lado del Prior Provincial y otros miembros del Consejo, en las celebraciones tenidas en Pavía los días 16-18 de octubre, con la presencia del Prior General Eustasio Esteban y de otras personalidades. Fue para él muy gozoso poder celebrar el día 15 la eucaristía sobre el sepulcro de San Agustín. Se lo comunicaba ese mismo día a la Comunidad de Medina: «Hoy me ha cabido la suerte de celebrar la S. Misa sobre el sepulcro del N. S. Padre. Como es natural, no me he olvidado de pedir por Uds.» ${ }^{10}$. Gozó también visitando algunos santuarios italianos, sobre todo de la Orden. Lo califica de «consuelos experimentados en Pavía, Loreto, Tolentino, Montefalco y Casia» ${ }^{11}$.

En Filipinas se entregó con intensidad, generosidad y fraternidad a promover la vida espiritual de la Congregación de Hermanas Agustinas de Filipinas, hoy Congregación de Agustinas de Ntra. Señora de la Consolación. Mención especial merecen los ejercicios espirituales que les predicó en Manila, comenzados el día 3 de abril de 1932. Se conservan en síntesis recogida por la Hna. Trinidad de la Encarnación con el título Directorio espiritual hecho por el Siervo de Dios Excmo. y Rvdmo. P. Anselmo Polanco para una religiosa residente en Manila. Es una preciosa síntesis de vida espiritual. La Hna. Trinidad fue la más asidua hija espiritual del P. Polanco entre las Hermanas de la Congregación. Es muy probable que el P. Polanco le aprobase la síntesis como Directorio espiritual para ella. Continuaron teniendo

9. Cf. Recuerdo de la consagración de la Iglesia del Smo. Nombre de Jesús de los PP. Agustinos de Valladolid, El Escorial 1930; Miguel CEREZAL, O.S.A., Inauguración de la nueva Iglesia de PP. Agustinos de Valladolid, en Archivo Agustiniano 33 (1930) pp. 462-465; A. POLANCO, Carta desde Valladolid, 17.VI.1930, a la Hna. Petra Garviras, Priora de las Agustinas de Clausura de Medina del Campo (Valladolid).

10. Carta desde Pavía, 15.X.1930, a las Agustinas de Medina del Campo; cf. Miguel de la PINTA Llorente, O.S.A., Fiestas del XV Centenario en Pavía, en Archivo Agustiniano 34 (1930) pp. 452-455.

11. Carta desde Roma, 24.X.1930 a la Priora de las Agustinas de Sancti Spiritus de Valladolid: les comunica que ese mismo día sale para España por haber recibido noticia de enfermedad grave de su madre. 
correspondencia hasta 1937. Las Hermanas apreciaban mucho al Beato Polanco. Fueron varias las que continuaron acudiendo a él por carta hasta en el tiempo de su pontificado.

Se aproximaba el Capítulo Provincial de 1932. No pasó por su mente que sería en él elegido Prior Provincial. Se le había encomendado tener en el mismo Capítulo el discurso de elección de Prior Provincial. Lo tuvo, habló, 'con exigencia, de las cualidades y virtudes que habían de adornar al que se eligiera. Recalcó a los capitulares la responsabilidad y el deber contraído ante Dios de obrar rectamente en conciencia sin dejarse llevar por egoísmo o segundas intenciones. El discurso comenzaba con el texto bíblico Suscitabo mihi sacerdotem (1 $\mathrm{R} 2,35)$. Era una buena radiografía del estado de la Provincia. Tal vez no hubiera exigido tanto si hubiera sabido que sería él el nuevo Prior Provincial. Así sucedió el día 30 de julio. Eran 42 los vocales. El Beato Anselmo fue elegido en la primera votación por 36 votos. Se sintió confundido, lloró; pero no rechazó la voluntad de Dios expresada por los capitulares. E inició su gobierno con férrea lealtad a cuanto había proclamado. En el mismo capítulo se determina fijar en Madrid ${ }^{12}$ la residencia del Prior Provincial y Consejo. Al Prior General Clemente Fuhl, que le preguntó cuáles eran las razones que lo aconsejaban, el P. Polanco respondió que se encontraba más en el centro geográfico de la Provincia, lo que facilitaba una comunicación más frecuente con los hermanos y con las fuerzas más vivas de la Provincia, como son las casas de formación.

El Beato Anselmo Polanco nunca consideró las leyes como una opresión o limitación de libertad. Las consideraba como una preciosa ayuda para conocer la voluntad de Dios. Aceptaba, con la mayor extensión de la ley, las palabras del salmo 118,105: Para mis pies antorcha es tu palabra, luz para mi sendero ${ }^{13}$. Se las aplicaba a sí mismo y las aplicaba a sus encomendados o súbditos. De ahí que pusiera tanto empeño en cumplirlas y en exigir su cumplimiento durante el ministerio de la solicitud pastoral que le exigieron dentro de la Orden Agustina los cargos de formador, Prior de la Comunidad de Valladolid y Prior Provincial, cargos que en la Orden Agustina han estado siempre revestidos de la misión pastoral de ayudar a los Hermanos en el camino de la perfección o santidad ${ }^{14}$.

12. Cf. Capitulum provinciale augustinianae Provinciae Smi. N. Iesu Insularum Philippinarum Manilae celebratum an. D. 1932, Zikaei-Shanghai 1932, p. 17.

13. Cf. Comentario El mayor de todos los salmo, 118.

14. Cf. Constitutiones Ordinis, revisión de 1290, cap. 31 y 33, en Ignacio ARAMBURU, O.S.A., Las primitivas Constituciones de los Agustinos (Ratisbonenses del año 1290), Valladolid 1966, nn. 224-225, 231, pp. 88-89; n. 280, p. 100; Constitutiones Ordinis, revisión de 1968, ed. de Roma, 1990. nn. 13 y 15, p. 21; nn. 310-311, p. 99. 
Se ha dicho con frecuencia que su forma de gobierno fue severa. Uno de los más entusiastas admiradores del Beato Polanco fue el P. Rafael Pérez González (+ 1993), Secretario provincial durante el Provincialato del Beato. Conocí muy bien al P. Rafael. Lo estimé y me estimó. Es más, accedió con mucha generosidad a mi ruego de dar una respuesta a las declaraciones proferidas por el P. Francisco Aymerich en el proceso de beatificación del P. Polanco. Aún más, tuvo conmigo la deferencia y delicadeza de entregarme su precisa y documentada respuesta, aunque ya hacía más de un mes que yo había acabado mi mandato de Postulador de la Orden de San Agustín ${ }^{15}$. Este buen agustino, de probada imparcialidad, pensando que sería poco menos que imposible que la Sede Apostólica accediese a declarar el martirio de los asesinados durante la persecución en España a partir de 1936, me aconsejó pedir que se continuara la causa por la vía o procedura de las virtudes; porque el conocimiento que tenía del P. Polanco y la experiencia adquirida en el tiempo en que había trabajado en la Congregación para las Causas de los Santos le hacían creer muy fundadamente que las virtudes del P. Polanco avalaban el éxito de su proceso por esta vía. Le convencí de la conveniencia de saber esperar a que el Papa concediese proceder por la vía del martirio; porque, aunque fuese fácil lograr la declaración de la heroicidad de sus virtudes, podía pasar un tiempo incalculable sin obtener el milagro exigido para la beatificación por virtudes, milagro que no se necesita para la beatificación por vía de martirio. Para el P. Rafael la santidad del P. Polanco era clara, sin que fuera obstáculo su severidad, la que no desmentía:

«Su norma en él (Provincialato) y en los demás cargos que desempeñó dentro de la Orden, fue el cumplimiento de la ley escrupulosamente mantenida. Tendia más a la rigidez, sin llegar a extremos de dureza, que a la benignidad, a pesar de su carácter afable y bondadoso. Y es que su índole psicológica y el concepto que se había formado de la cuestión de la observancia le llevaba a las márgenes de los escrúpulos de conciencia. Por esta razón abominaba de la laxitud y no toleraba el menor descuido, porque temía que por ese resquicio se pudiesen introducir morbosos accidentes de la relajación y de la inobservancia, a la que había declarado guerra sin cuartel» ${ }^{16}$.

15. Cf. Summarium additum, pp. 2-74, donde se publica, entre los «Documenti extraprocessuali», la respuesta del P. Rafael, Promotor General de la fe emérito de la Congregación para las Causas de los Santos. Es un documento muy valioso para conocer la vida y espíritu del beato.

16. Rafael PEREZ, O.S.A., Breve biografía del P. Anselmo Polanco, Obispo de Teruel, dactilografiado en nueve páginas, con título y firma autógrafos, en Valladolid, Archivo Provincia Agustina de Filipinas (APAF) 1287. 
Ciertamente el P. Polanco quiso y se esforzó por ejercer la autoridad, buscando más ser amado que temido. Así afirma que ha de proceder el superior para serlo según san Agustín, quien expone admirablemente en el cap. 11 (hoy 7, n. 46) de la Regla las dotes que ha de tener el superior: «... Sométase de buen grado a la disciplina regular e impóngala prudentemente a los demás; $y$, aunque ambas cosas sean necesarias, prefiera antes ser amado que temido de los súbditos...». «Humildad sincera, ejemplaridad constante, gran dosis de prudencia, entrega exenta de dureza y de debilidad, y caridad a la vez fuerte y sufrida..., he aquí las prendas que, según nuestro santo Patriarca, han de adornar al Superior». El Superior ha de tener «entereza de espíritu bastante flexible para no acabar de quebrar la caña rota (cf. Is 42,3; Mt $12,20)$ y bastante enérgica y tenaz para no desmayar a la vista de los peligros, ni retroceder ante las dificultades o malquerencias» ${ }^{17}$.

El P. Polanco no nació santo, sino que fue haciéndose santo con una colaboración ardiente a la gracia de Dios. Parte de esa severidad que se le ha adjudicado pertenece a la inexperiencia de la juventud. A los 26 años se le había nombrado ayudante del Maestro de jóvenes profesos de Valladolid y a los 28 Maestro. El mismo P. Amador del Fueyo declara que la experiencia le fue curtiendo en sus actuaciones de superior.

«Al final de su Provincialato -afirma el P. Fueyo-el P. Anselmo ya no parecía el mismo. Los viajes, la experiencia del mundo, el conocimiento de las realidades, desengaños quizá o tardías contriciones, le ablandaron el criterio, haciéndole dúctil y maravillosamente comprensivo, y hasta su voz y continente se tornaron más apacibles.

Cuando el P. Polanco llegó al Episcopado, tenía un no sé qué de augusto y venerable» ${ }^{18}$.

En su gobierno se inspiró no poco en las exigencias y actuación del eminente Prior General Eustasio Esteban. Se identificó con él en la solicitud por la promoción de las vocaciones, por la restauración de las Provincias de Perú y Colombia. La restauración de la de Perú, porque era un deber de la Provincia del Santísimo Nombre de Jesús de Filipinas hacer cuanto se pudiera para cumplir la misión que le había confiado el Prior General P. Tomás Rodríguez, también, como el P. Eustasio, miembro de la Provincia de Filipinas, de restituirle lo más pronto posible la plenitud de gobierno, que la había

17. Anselmo POLANCO, Discurso Suscitabo mihi sacerdotem (1 R 2,35) al Cap. Prov. de 1932; sobre el Beato Anselmo Polanco y la vida religioso-agustina, cf. la intensa y preciosa síntesis del P. Provincial de la Prov. del Smo. Nombre de Jesús de Filipinas Miguel PASTOR, El $P$. Anselmo Polanco modelo de religioso agustino al servicio de la Iglesia.

18. Amador del FUEYO, ob. cit. p. 47. 
sido limitada en 1902 en busca de lograr un florecimiento a base sobre todo de vocaciones nativas. Esta y otras lecciones tuvo una ocasión hermosa de aprenderlas en el Capítulo Provincial de Valladolid de 1929, en el que fue hecho Definidor, cargo que le ofrecía en el Capítulo un influjo muy superior al que tiene hoy un Consejero. El Capítulo fue presidido por el P. Eustasio y en su desarrollo y determinaciones aparece transparente su intervención ${ }^{19}$. El Beato Anselmo coincidía con el P. Eustasio hasta en la importancia que tiene en el florecimiento de una institución el cumplimiento exacto de las leyes: Constituciones, Ritual, Estatutos...

«... lógico es concluir recomendándoos -escribía el 3 de septiembre de 1932 en la carta circular de saludo a la Provincia como nuevo Provincial- el estudio asiduo y la diligente observancia de la legislación canónica y constitucional, que ha de ser luz que ilumine nuestros pasos en los ásperos senderos que conducen a la Patria. ¿De qué nos serviría tener leyes santísimas si las ignorásemos $o$, indiferentes, hiciéramos caso omiso de sus prescripciones? $Y$ ese deber de conocerlas y de obrar en conformidad con lo que disponen, incumbe de un modo principalísimo a los Superiores, quienes, además de ajustar su conducta a las normas eclesiásticas comunes y particulares, han de velar cuidadosamente a fin de que los súbditos las guarden» ${ }^{20}$.

Estas sus palabras son una magnífica resonancia de cuanto el P. Eustasio escribió en la carta-presentación de la nueva revisión de las Constituciones el 16 de mayo de 1926, sobre todo en la parte conclusiva ${ }^{21}$.

Cuando se acercaba el final del trienio de su gobierno provincial y la celebración del Capítulo, el Papa Pío XI lo nombraba el día 21 de junio de 1935 Obispo de la diócesis de Teruel y Administrador Apostólico de Albarracín con enorme sorpresa suya, pues se creía indigno e incapaz ante tamaña dignidad y responsabilidad. Lo había presentado y promovido el Arzobispo de Valladolid D. Remigio Gandásegui, de quien era confesor. Le había movido a ello, según su propia declaración, «su afabilidad en la conversación y su prudencia en el gobierno, y porque su delicadeza no estaba exenta de la necesaria severidad y regía a sus súbditos, no con el imperio del mando, sino con el ejemplo de la vida» ${ }^{22}$.

19. Cf. Capitulum provinciale augustinianae Provinciae Smi. N. Iesu Insularum Philippinarum Vallisoleti celebratum an. D. 1929, Valladolid 1929.

Sobre la promoción de vocaciones y la restauración de las provincias citadas, cf. Miguel PASTOR, Ob. cit. pp. 36-38.

20. Anselmo POLANCO, Provincia del Santísimo Nombre de Jesús de Filipinas. Circular, Manila 1932, pp. 5-6.

21. Eustasio ESTEBAN, Litterae Rvmi. P. Generalis, en Constitutiones, ed. de Roma 1926, pp. IX-XIX, sobre todo p. XVII.

22. Mariano RODRÍGUEZ HERRERo, O.S.A. De consecratione Rvmi. P. Anselmi Polanco et 
Llegó el Capítulo Provincial. Se celebró en Bilbao los días 18-27 de julio de 1935. Antes de hacerse público su nombramiento episcopal, se daba por cierto que el Beato Anselmo sería reelegido Prior Provincial. Aunque se sobreponía el gozo de verlo nombrado Obispo, muchos capitulares sintieron que la Provincia se viera obligada a perder tal Prior Provincial. Aun a sabiendas de no poder elegirlo, 18 de los 48 vocales le dieron su voto, aunque no tendría más valor que el testimonial ${ }^{23}$.

El P. Polanco participaba en el Capítulo y firmó las Actas como Prior Provincial cesante. Presentó al capítulo una precisa relación del estado de la Provincia con sus luces y con sus sombras. La tituló Memoria presentada por el Muy Rvdo. Padre Provincial Fr. Anselmo Polanco al capítulo de 1935. Es larga, densa, sumamente sincera e imparcial. No tuvo miedo a poner el dedo sobre la llaga. Una nueva radiografía de su Provincia religiosa agustina del santísimo Nombre de Jesús de Filipinas. Ocupa siete folios y medio, de formato de oficio, escritos a máquina a línea seguida. Es difícil encontrar otra relación capitular tan completa, tan sincera y tan imparcial. A pesar de ello, el P. Polanco se siente contrariado de no haberla podido hacer como deseaba, por habérselo impedido el nombramiento de Obispo. Expresa este pesar en la introducción:

«Era mi propósito presentar al próximo Capítulo -la firma en Madrid el 16 de julio de 1935- un extenso y bien documentado informe acerca del estado de nuestra Provincia, que pudiera servir de base para tomar ciertas medidas indispensables, a juicio del que suscribe, si es que ha de llevar la vida digna de su historia y floreciente en todos los órdenes. El hecho de haber visitado las casas que la forman y la observación y estudio atento de sus necesidades me ponían en condiciones de realizar el proyecto; pero circunstancias imprevistas me han venido a trastornar los planes; $y$ muy a pesar mío, pues, hijo agradecido de tan preclara madre, siento verdadero interés por aumentar su crédito y prestigio, he de limitarme a ofrecer a los V.V. Padres Capitulares un indice de asuntos sobre los cuales deberán deliberar y hacer que recaigan acuerdos prácticos. La falta material de tiempo no me permite otra cosa».

El Provincialato del P. Polanco se impuso como modélico en el ambiente y en el recuerdo de los más por su inspiración espiritual y por la eficiencia decidida e imparcial en su actuación. En el escrito anónimo aparecido en 1952 bajo el título Solis presbyteris, sugiriendo ideas y proponiendo medios a

et de eius ingressu in dioecesim Terulensem, en Analecta Augustiniana 15 (1933-1936), pp. 256259; las palabras citadas, en la p. 259.

23. Capitulum provinciale Provinciae Sm. N. Iesu Insularum Philippinarum Ord. Er. Sancti Augustini in domo de Bilbao celebratum an. D. 1935, Bilbao 1935, pp. 7-8. 
la Comisión preparatoria del Capítulo General de 1953 para un relanzamiento eficaz de la Orden Agustina, al hablar de las visitas canónicas o de renovación bajo el epígrafe ¿Visitas? ¿Tiempo perdido?, se afirma: «Pero el colmo del mal es que las visitas también son muchas veces inútiles. A muchos he oído decir que en las visitas se pierde el tiempo y el dinero. Llega el Visitador a una casa, se celebra su llegada lo mejor que se puede, se le obsequia durante unos días... Se despide afectuosamente y todo sigue como antes. No digo que siempre sea así, pero muchas veces es así... Me acuerdo ahora de Visitadores tan santos como el P. Polanco, el P. Fuhl y otros, vivos y muertos. Yo besaría el polvo que ellos pisaron» ${ }^{24}$.

Mientras tanto se había ido preparando todo para el día de la consagración episcopal. La tarjeta-invitación a la ceremonia estaba primorosamente escrita y decorada. El texto era como sigue:

«El Excmo. y Revmo. Sr. D. Fr. Anselmo Polanco y Fontecha, O.E.S.A., Obispo electo de Teruel y Albarracín será consagrado, Dios mediante, el 24 de agosto de 1935, a las nueve de la mañana, en la iglesia del Colegio-Seminario de los RR. PP. Agustinos de Valladolid, por el Excmo. y Rvdmo. Sr. Dr. D. Federico Tedeschini, Arzobispo de Lepanto y Nuncio Apostólico en España, asistido de los Excmos. y Rvmos. Sres. Don Remigio Gandásegui y Gorrochátegui, Arzobispo de Valladolid, y Don Manuel de Castro Alonso, Arzobispo de Burgos, siendo padrinos Don Ricardo Cortés Villasana, Diputado a Cortes, y $D^{a}$ Concepción Vargas Zúñiga y Jaraquemada, Condesa de Villanueva.

Tanto los padrinos como el consagrando se honran al invitar a $V$. a la augusta ceremonia» 25 .

Las cosas no se realizaron totalmente de acuerdo con lo anunciado. A ninguno de los Obispos consagrantes le correspondió ejercer la misión confiada, aunque se haya dicho lo contrario hasta en documentos bastante oficiales. No pudieron participar en la consagración el Sr. Nuncio y el Arzobis-

24. Solis presbyteris, ff. 38 y 41; recoge el pensamiento, sobre diversos temas, de agustinos ilustres, como los PP. Mariano Rodríguez Herrero, César Vaca, Lope Cilleruelo... Su autor, sin embargo, fue el P. Pedro Alvarez González, agustino de la Provincia de Castilla, definidor en el Capítulo General de Roma de 1920, profesor en Calahorra, pasó en 1930 a Puerto Rico, donde fue Vicario Provincial y murió, en San Germán, en 1959; escribió el libro Biografía de la Excelentísima Señora Doña Pascuala Cascajares y Azara, Barcelona 1926 (cf. Isacio RODRIGUEZ R.-Jesús ALVAREZ F., O.S.A., Labor científico-literaria de los Agustinos españoles, vol. I (1913-1964), Madrid 1992, p. 47). En su carta al director de la Revista Archivo Agustiniano, P. Pedro Martínez Vélez, desde Calahorra (Logroño), en 1929, publicada bajo el epígrafe Indicación de algunas ideas, en Archivo Agustiniano 32 (1929) pp. 313-316, propone en síntesis algunas de las mismas ideas de Solis presbyteris. Este folleto se compone de $50 \mathrm{ff}$. mimeografiado en letra pequeña y a línea seguida. Biografía de Pedro Alvarez González en Acta O.S.A. 4 (Roma 1959), p. 82.

25. Logroño, Archivo del Convento de Agustinas de vida contemplativa, C/. Santa Rita, s/n. 
po de Valladolid, por motivos de enfermedad. Así el Arzobispo de Burgos, tan amigo siempre de los Agustinos, pasó a ser el Obispo consagrante, asistido por el Obispo de Vitoria, Mateo Múgica, hermano del agustino Juan Múgica y uno de los dos Obispos españoles que no firmaron la carta colectiva del 1 de julio de 1937, y por el Obispo de Osma Tomás Gutiérrez, tío del agustino P. Conrado Rodríguez Gutiérrez y condiscípulo del beato Polanco en los estudios de la preceptoría de Barriosuso (Palencia) ${ }^{26}$.

El 7 de octubre de 1935 firma en el colegio de San Agustín de Zaragoza su primera carta pastoral, la Carta de saludo y de proyecto fundamental de su tarea episcopal, a sus diocesanos de Teruel y Albarracín. Comienza con las palabras La insospechada designación. Se pone a disposición de todos. «Es Dios mismo -declara- quien, sin méritos de nuestra parte, ha querido encumbrarnos y servirse, conforme a sus designios providenciales, de nuestra insignificancia en la obra excelsa y difícil del régimen y dirección de los fieles en estas amadas diócesis de Teruel y Albarracín». «Está dispuesto a sufrir la muerte por ellas (las ovejas) como el Buen Pastor Jesús, modelo y dechado de Pastores». Su gobierno de las personas encomendadas quiere realizarlo, aunque no cite su nombre, según lo que prescribe San Agustín en varios escritos, inclusive en el cap. 7, n. 46, de su Regla. «Es necesario que (el Obispo), en el cumplimiento de su oficio, reprenda a los díscolos, consuele a los tristes, aliente a los pusilánimes, trate con benignidad a los enfermos, sea paciente y sufrido, prudente en sus determinaciones, discreto, severo sin exageración, en resumen: espejo de virtud, reflejo de las perfecciones de Cristo, a quien representa, caritativo haciéndose todo para todos a fin de ganarlos a todos». Diversas veces cita a su patriarca y padre espiritual San Agustín, en cuya doctrina se basa y a cuyos ejemplos de vida pastoral se reclama. Pretende seguir también el ejemplo episcopal de sus Hermanos agustinos, uno de ellos, «el esclarecido Sr. D. Fr. Andrés Aznar Naves», le precedió en la diócesis de Teruel. Quiere seguir el ejemplo de todos sus predecesores en Teruel. Esto le estimula y le obliga a trabajar con todas sus fuerzas; «pero, si a esto se agrega nuestra condición de hijo de San Agustín, sol de la Iglesia y lumbrera del Episcopado católico, y el ser, -añade- por consiguiente, miembro de la familia por él fundada, de la que, aquí en España, salieron, entre otros innumerables y prestigiosos Prelados, un Santo Tomás de Villanueva, el Padre de los Pobres, y en nuestros días los Excmos. Sres. Cámara, López, Valdés, Zacarías, Bernardo y Colom, se impone con mayor fuerza el deber de conservar el rango de nobleza que por estos títulos nos corresponde».

26. Cf. Mariano Rodríguez Herrero, Art. cit. pp. 256ss; Anselmo POLANCO, Memorandum, 1932-1935, días 19-24 de agosto de 1935 (Ms. autógrafo, en Valladolid, APAF). 
Al final de la carta aparece impreso su escudo episcopal con los diseños de la insignia de la Orden Agustina -el corazón traspasado por el dardo de la palabra de Dios, ardiendo en llamas de amor, colocado sobre el libro de la Biblia-y de la imagen del Santo Niño de Cebú, como símbolo de su Provincia agustina. Siguen los diseños de los escudos de Teruel y Albarracín. Y debajo está la frase bíblica, lema de su episcopado: Impendam et superimpendar pro animabus vestris. No he visto que la usara en traducción española. Mientras no conste lo contrario, se ha de suponer que comprendió su verdadero sentido: Yo gastaré (todo) y me desgastaré por vuestras almas. La traducción «me gastaré y desgastaré» no corresponde a San Pablo (2 Cor 12,15).

Una carta llena de vida de quien en Cristo Jesús quería ser vida para $\operatorname{todos}^{27}$.

El mismo día 7 de octubre entraba solemnemente en Teruel. Así esquemáticamente lo anotó en su citado Memorandum:

«Día 7. Salida (de Zaragoza) a las 2 para Teruel: siete autos - Gran recibimiento en Torrelacárcel, Calamocha, Villarquemada, etc. - En los Paúles a las 6,30 - Presentaciones - Noticia de la desgracia ocurrida al Sr. Monterdo Medidas - Cena y cama en los Paúles.

8. La santa Misa - Comisiones - A las 3,30 salida de los Paúles en auto Colgaduras - Gentío inmenso - En el óvalo y en la Catedral - Tedeum, besamanos, plática, etc. - En Palacio - Desfile de personas» ${ }^{28}$.

Poco tiempo gobernó su diócesis y durante ese poco tiempo lo hizo en circunstancias muy difíciles y heroicas. El 8 de enero de 1938 fue encarcelado. Entonces empezó su duro calvario. El 7 de febrero de 1939 era fusilado, junto con su Vicario General Felipe Ripoll y otros, en el barranco llamado Can Tretze, en las cercanías de Pont de Molins (Girona). Sin duda fue la oblación más completa que ofreció a la Santísima Trinidad en toda su vida. Después rociaron sus cuerpos con gasolina para quemarlos y hacerlos desaparecer. Tal vez por las prisas en huir, no lo lograron. Al P. Polanco y a D. Ripoll apenas les alcanzó el fuego ${ }^{29}$. Juan Pablo II, al declararlo Beato el día 1 de octubre de 1995, no hizo más que declarar su fidelidad a Cristo Jesús y a su Iglesia, hasta derramar su sangre, poniéndolo como modelo de vida a los cristianos. Se ha dicho que su muerte fue motivada por haber firmado la

27. Publicada en el Boletín Oficial Eclesiástico de las diócesis de Teruel y Albarracín 76 (1935), pp. 107-117.

28. Es un error, pues, poner la entrada en Teruel el día 8.

29. Sobre su fusilamiento y otros particulares del encuentro y reconocimiento de su cadáver hay abundantes y claros testimonios en el proceso de Beatificación. Cf. Positio super martyrio; Teófilo APARICIO, Ob. cit. pp. 107-151. 
Carta Colectiva de los Obispos españoles del 1 de julio de 1937. Es una afirmación carente de fundamento. Otros que no la habían firmado, como D. Ripoll, también fueron fusilados.

Se ha repetido, como si fuera una gloria para él, que las autoridades de la República le ofrecieron nombrarlo Obispo de Barcelona, cuando se encontraba encarcelado en la misma ciudad. Aun en el caso de que hubiera sido verdad, se le condicionaba a una «contrapartida» que de ningún modo podía aceptar su fidelidad a la Sede Apostólica, a la que corresponde el nombramiento de los Obispos: retirar su firma de la Carta Colectiva. El P. Rafael Pérez lo declara así en el Proceso de Beatificación:

«Sé que el Siervo de Dios fue invitado a retirar su firma de la Carta colectiva del Episcopado español, a cambio, no sólo de la libertad, sino también de nombrarle Obispo de Barcelona. La respuesta del P. Polanco fue que aceptaría tal nombramiento, si se lo ordenaba el Santo Padre. Lo sé de referencias» ${ }^{30}$.

Preguntado posteriormente el P. Rafael sobre la verdad y objetividad de la afirmación, respondió que no se podía probar. Una cosa es clara. El P. Polanco no recibió el don del martirio por sorpresa, sin tener oportunidad de arrepentirse o de dar marcha atrás. Lo fue por una aceptación responsable, madurada por más de un año. De ahí que no se pueda por menos de asumir la paladina afirmación del P. Amador del Fueyo:

«No hubo (en la persecución religiosa de España...) un mártir de la fe más indiscutible que Fray Anselmo Polanco y Fontecha, obispo de Teruel» ${ }^{31}$.

\section{ESCRITOS}

\section{1) Escritos publicados}

El Beato Anselmo Polanco no escribió ningún libro. Fue muy poco lo que publicó. Invitado a escribir en la revista agustina de su Provincia del Santísimo Nombre de Jesús de Filipinas, España y América, publicó dos articulitos, dos cuentos. Son cuentos históricos. El primero se titula ;Tú no eres para este mundo!... Historia que parece cuento. Lo publica en 1906 y refiere la vida y muerte de su hermana, que murió muy niña y cuyas vivencias y recuerdos dejaron profunda impresión en los sentimientos del joven Ansel-

30. Positio super martyrio, Summarium, p. 97.

31. Amador del FUEYO, Los Agustinos en la revolución y en la cruzada, Bilbao 1947, p. 362. 
mo. El segundo también es histórico. Lo publica en 1908 y se refiere a la existencia brevísima de su hermano. Lo tituló Pedrín (Cuento) ${ }^{32}$. En ellos se advierte que el joven Anselmo, a pesar de aparecer a primera vista un tanto seco, era bastante emotivo y afectuoso. Lo mismo se demuestra en su correspondencia epistolar con sus amigos y con las religiosas agustinas.

El P. Amador del Fueyo califica estos dos artículos de «copias del natural muy vivas, muy sinceras, pero de haber llegado a escritor -añade- no hubiera sobresalido en ese género de narración, o mucho nos equivocamos. No escribió, pues, e hizo bien -continúa-; no obstante, si la obediencia le hubiese llamado a los rudos afanes de la pluma, habría sido un gran expositor de ideas. Odiaba en los escritores, y más en los religiosos, el autobombo, la profusión verbalista, la inurbanidad en la polémica y el desenfado petulante con que algunos mequetrefes se arrojan a temas que no dominan. Él era humilde, sincero y cauto; prototipo de la densidad y hombría de bien intelectual y moral» ${ }^{33}$.

En función de su cargo de Prior Provincial publicó en 1932 una Circular a los Hermanos de la Provincia. Les envía su primer saludo oficial, sin dejar de ser eminentemente paternal y fraternal, señala el programa fundamental de su gobierno y manifiesta los sentimientos que le embargan ante la situación socio-política sobre todo de España ${ }^{34}$.

Los otros escritos publicados son Cartas pastorales, exhortaciones y comunicaciones a las diócesis de Teruel y Albarracín. Las publicó en el Boletín oficial eclesiástico de las diócesis de Teruel y Albarracín (BOEDTA).

1. Carta pastoral "La insospechada designación» (Zaragoza, Colegio de San Agustín, 7 de octubre de 1935). Es la carta saludo a sus fieles y declaración de las líneas fundamentales que le animarán en el gobierno de las dos diócesis ${ }^{35}$.

2. Mes de la caridad. Exhortación a la Acción Católica y demás fieles a colaborar durante los días 15 de diciembre - 15 de enero con obras de beneficencia en favor de los necesitados (Teruel, 20 de diciembre de 1953) ${ }^{36}$.

3. Circular sobre las próximas elecciones (Teruel, 21 de enero de 1936). Se dirige a los fieles y sobre todo a los sacerdotes ${ }^{37}$.

4. Cumplimiento pascual (Teruel, 4 de febrero de 1936) ${ }^{38}$.

32. Artículos publicados en España y América 12 (1906), pp. 438-447; 17 (1908), pp. 571573.

33. Amador del FUEYO, Héroes de la epopeya, pp. 39-40.

34. Cf. la nota 20 ; son 9 pp. de $18 \times 12 \mathrm{cms}$.

35. BOEDTA. 76 (1935), pp. 107-117.

36. BOEDTA. 76 (1935), pp. 171-173.

37. BOEDTA. 77 (1936), pp. 27-31.

38. BOEDTA. 77 (1936), pp. 31-32. 
5. Circular sobre la celebración del día de Papa (Teruel, 31 de enero de 1936) ${ }^{39}$.

6. Circular sobre cultos en Carnaval (Teruel, 3 de febrero de 1936) ${ }^{40}$.

7. Santa Cuaresma (Teruel, 3 de febrero de 1936) ${ }^{41}$.

8. Exhortación pastoral al clero y fieles de las diócesis de Teruel y Albarracín (sobre la oración) (Teruel, 29 de diciembre de 1936). Ofrece un pequeño tratado sobre la oración. Se revela a sí mismo como hombre muy experimentado en la oración, que sabe sacar las conclusiones prácticas ${ }^{42}$.

9. Exhortación pastoral sobre la manera de proceder de los sacerdotes en las presentes circunstancias (Teruel, 20 de marzo de 1936) ${ }^{43}$.

10. Edicto (anunciando la Visita pastoral) (Teruel, 10 de mayo de 1936) ${ }^{44}$.

11. Circular acerca de la Santa Visita pastoral. Advertencias $e$ instrucciones (Teruel, 11 de mayo de 1936) ${ }^{45}$.

12. Sobre el novenario de preces al Espíritu Santo (18 de mayo de 1936) ${ }^{46}$.

13. Aniversario y Consagración de España al Sagrado Corazón de Jesús (Teruel, 15 de mayo de 1936) ${ }^{47}$.

14. Circular. Mes dedicado al Sagrado Corazón de Jesús (Teruel, 18 de mayo de 1936) ${ }^{48}$.

15. Exhortación sobre la Jornada Misional del Dolor (Teruel, 16 de mayo de 1936) ${ }^{49}$.

16. Día de la Prensa Católica (Teruel, 4 de junio de 1936) ${ }^{50}$.

17. Al clero y fieles de nuestras diócesis de Teruel y Albarracín (Teruel, 25 de noviembre de 1936). Hace una breve exposición de la triste situación del momento y exhorta a todos a colaborar con la vida y el trabajo, para rehacer cuanto se necesite, pidiendo perdón a Dios por nuestros pecados. Aprovecha la proximidad del tiempo de Adviento ${ }^{51}$.

18. Bendición papal (Teruel, 30 de noviembre de 1936). Exhortación para ganar la indulgencia con motivo de la fiesta de la Inmaculada ${ }^{52}$.

39. BOEDTA. 77 (1936), p. 32.

40. BOEDTA. 77 (1936), p. 33.

41. BOEDTA. 77 (1936), pp. 33-35.

42. BOEDTA. 77 (1936), pp. 41-52.

43. BOEDTA. 77 (1936), pp. 66-74.

44. BOEDTA. 77 (1936), pp. 130-131.

45. BOEDTA. 77 (1936), pp. 131-134.

46. BOEDTA. 77 (1936), pp. 134-135.

47. BOEDTA. 77 (1936), pp. 135-138.

48. BOEDTA. 77 (1936), pp. 138.

49. BOEDTA. 77 (1936), pp. 141-142

50. BOEDTA. 77 (1936), pp. 162-164.

51. BOEDTA. 77 (1936), pp. 213-214.

52. BOEDTA. 77 (1936), pp. 215. 
19. Nombramiento de Vicario Castrense (Teruel, 31 de julio de 1936). Hace algunas consideraciones sobre el ministerio pastoral ${ }^{53}$.

20. Preces por la salud del Papa (Teruel, 30 de diciembre de 1936). Ante el agravarse del Papa Pío XI, hace algunas consideraciones ${ }^{54}$.

21. Agradecimiento del Prelado (con motivo de las fiestas de Navidad) (Teruel, enero de 1937) ${ }^{55}$.

22. Circulares sobre el cumplimiento pascual (Teruel, enero de 1937) ${ }^{56}$.

23. Circulares sobre copias de partidas y cuentas de Fábricas (Teruel, 30 de enero de 1937) ${ }^{57}$.

24. Exhortación pastoral. Al clero y fieles de nuestras diócesis de Teruel y Albarracín (Teruel, 14 de marzo de 1937). Es una exhortación a levantar el ánimo, porque ya casi se ha logrado vencer el mal. Es necesario cooperar ahora a la obra de restauración ${ }^{58}$.

25. Aniversario de la consagración de España al Sagrado Corazón de Jesús (Teruel, 15 de mayo de 1937) ${ }^{59}$.

26. Circular sobre el mes del Rosario (Teruel, 24 de septiembre de 1937) ${ }^{60}$.

27. Circular sobre el Jubileo en sufragio de los difuntos (Teruel, 15 de octubre de 1937) ${ }^{61}$.

\section{2) Escritos inéditos.}

Con motivo de la instrucción del proceso de declaración de martirio o de beatificación se procuró, como lo exigen las leyes de la Iglesia, recoger todos sus escritos por insignificantes que fueran, éditos e inéditos: artículos, discursos, sermones, apuntes o esquemas de conferencias o pláticas, cartas. Todos, copiados a máquina, fueron enviados a Roma a la Congregación para las Causas de los Santos, llamada entonces Congregación de Ritos, por ser de su competencia todo lo referente al culto divino o liturgia. Fueron copiados en folios de tamaño o formato de oficio. Todo junto, incluidos los escritos publicados, que acabo de reseñar, suman 298 folios, escritos generalmente a línea seguida. Es un buen número.

53. BOEDTA. 77 (1936), pp. 215-217.

54. BOEDTA. 77 (1936), pp. 249-250.

55. BOEDTA. 77 (1937), pp. 250.

56. BOEDTA. 77 (1937), pp. 250-251.

57. BOEDTA. 77 (1937), pp. 251-252.

58. BOEDTA. 77 (1937), pp. 255-266.

59. BOEDTA. 77 (1937), pp. 309-310.

60. BOEDTA. 77 (1937), pp. 459-461.

61. BOEDTA. 77 (1937), pp. 493-494. 
1. 16 Sermones o discursos, que suman $66 \mathrm{ff}$. Algunos de estos sermones o discursos fueron elaborados antes de su ordenación sacerdotal, mientras el último es el que dirigió al Capítulo Provincial de 1932. Su contenido es: la Inmaculada, fiesta de Pentecostés, Buen Pastor (Jn 10,11), elección de Prior Provincial en 1932, Salmo 138, 3-4, sobre la sociedad, Sagrado Corazón de Jesús, Santa Rita, sobre la oración (Jn 16, 23), sacerdocio, hambre de Dios y juicio (J1 2, 21), Beato Juan de Rieti (en latín), fiesta de la Purificación de María, sermón para Adviento (Mt 11, 3ss), Santa Mónica, San Agustín.

2. Varias Pláticas religiosas: sobre el beneficio de la vocación, la perfección, la oración, el capítulo de culpas, el verdadero sacrificio, método de vida de fray Anselmo (1897), etc.

3. La ya citada Memoria presentada por el muy Rvdo. P. Provincial Fr. Anselmo Polanco al Capítulo de 1935 (8 ff).

4. Pláticas. 1934 (Beato Orozco). Son 9 ff. con la síntesis de las conferencias que dirigió a un grupo de señoras que hicieron los ejercicios espirituales en 1934 bajo su dirección en la antigua iglesia del Beato Alonso de Orozco de Madrid. Su contenido es precioso. Él mismo anota que son como un extracto del libro de LEFEVRE: Misión y virtudes sociales de la esposa cristiana.

5. Proyecto de los Estatutos de la Provincia del Santísimo Nombre de Jesús de Filipinas. El P. Polanco fue el principal redactor, siendo Definidor Provincial. A este proyecto corresponden los Estatutos publicados en $1930{ }^{62}$.

6. Pláticas varias sobre la vida religiosa.

7. Correspondencia con las Agustinas de Sancti Spiritus de Valladolid. 20 Cartas.

8. Correspondencia con varias religiosas Agustinas. 9 cartas.

9. Correspondencia con las Agustinas de Medina del Campo. 7 cartas.

10. Correspondencia con la capuchina M. Pilar Elizalde. 7 cartas.

11. Correspondencia con la Hna. Rita de la Concepción, Agustina de Filipinas. 7 cartas.

12. Correspondencia con el sacerdote de Teruel D. Roque Escuder. 6 cartas.

13. Correspondencia con el sacerdote de Teruel Alberto López Polo. 4 cartas.

14. Correspondencia con el sacerdote de Teruel D. Cosme Artigot. 4 cartas.

15. Correspondencia diversa. 19 cartas.

16. El ya citado Directorio espiritual, para la Hermana Trinidad de la Encarnación, Agustina de Filipinas. 1930.

62. Cf. Estatutos de la Provincia del Santísimo Nombre de Jesús de Filipinas, El Escorial 
17. Memorandum. Año 1932-1935. Es como un diario, muy esquemático, de los años que fue Prior Provincial y que prolongó hasta el 25 de octubre de 1935. Es documento precioso para conocer sus viajes y las personas con quienes trataba.

18. Más correspondencia. Son 20 cartas a Agustinos, Agustinas, etc.

Todo este material está contenido en la primera carpeta enviada a la Congregación de Ritos. Fueron enviadas otras 5 carpetas con el siguiente contenido:

Carpeta 2. Correspondencia oficial con los Superiores de Perú y Colombia. $32 \mathrm{ff}$.

Carpeta 3. Nueva remesa de cartas a las Agustinas de Filipinas. La mayor parte es dirigida a la Hna. Trinidad de la Encarnación. En total, 37 cartas.

Carpeta 4. Cartas al P. Gabriel Pérez, agustino. 16 cartas. Esta carpeta también contiene una carta al agustino alemán $P$. Pedro Leischner, escrita desde La Vid el 6 de mayo de 1921, la que llegó a Roma en otra carpeta.

Carpeta 5. a) Esquemas de pláticas a la Comunidad de Agustinos de Valladolid con motivo de tomas de hábito, profesiones, capítulos de renovación, etc. Son 26.

b) Varias cartas del Siervo de Dios recibidas a última hora para el proceso. Son 6 cartas al P. Mariano Rodríguez, agustino de Barriosuso, muerto en Roma en 1962, a la edad de 94 años y medio.

Carpeta 6. Contiene los escritos de su gobierno episcopal, ya mencionados entre los impresos en el BOEDTA.

Todos estos escritos nos proponen con toda claridad su doctrina, hasta aquellos que aparecen como sencillos esquemas o son cartas que a primera vista podrían creerse de escaso o de ningún valor. Unos y otros revelan el alma trasparente del Beato Anselmo en su vida espiritual. Revelan su vida. Sabemos que cuanto escribía y recomendaba lo tenía muy asumido en la vivencia de cada día y era fruto maduro de su profunda interioridad. Como el Divino Maestro, como su padre espiritual San Agustín, el Beato Anselmo primero practicaba y después enseñaba (cf. Hch 1,1 ). De ahí su fuerte libertad interior, por la que no se dejaba intimidar de nadie, a pesar de ser por temperamento un tanto tímido y retraído.

$\mathrm{Su}$ doctrina refleja la madurez de quien se prepara bien y medita la lección antes de proponerla. Ciertamente no puede decirse de él la afirmación, aplicable a más de los que se puede creer, de que primero hablan y después piensan. Sus escritos confirman la declaración del P. Amador del Fueyo:

"Cuando fue Rector de Valladolid, y después fue Provincial y Obispo, habló muchas veces a las Comunidades y al público, y aún se guarda memoria de 
algunas. En Iquitos, por ejemplo, predicó a las Asociaciones piadosas con tanto fervor, que las señoras, prendadas de su gran espíritu, le desearon para Obispo de allá; en Teruel se hacen lenguas de sus pláticas y alocuciones, singularmente cuando el asedio; nosotros le oímos una sola vez, y nos llenó las medidas. Raramente se dejaba ir al hilo de la improvisación, ni aun sobre caminos trillados; mal que bien se trazaba por escrito un esquema muy breve, trabado y completo» ${ }^{63}$.

De algo de esto se dio cuenta el humilde Polanco. Después de haber predicado los ya citados ejercicios espirituales a señoras en la iglesia del Beato Alonso de Orozco de Madrid, escribía a su muy amigo agustino P. Gabriel Pérez, Rector de Santa María de la Vid, el día 22 de marzo de 1934:

«Te voy a comunicar una noticia que de seguro ha de agradarte. jAdmírate! Me he atrevido a dar ejercicios espirituales en esta iglesia del Beato Orozco. Y el caso es que la gente ha quedado contenta y yo... casi persuadido de que he errado la vocación. Más éxitos obtendría y menos disgustos dedicándome a esa clase de tareas que actuando de Provincial. Te lo digo en reserva: cada día se me hace más pesada la carga. ¿No te ocurre a ti lo mismo con la tuya?».

Excepto en los sermones de los primeros tiempos, que los compone un poco al estilo literario del célebre Luis Calpena, su estilo es sencillo y diáfano, sin grandes pretensiones literarias.

\section{LA DOCTRINA}

Su doctrina es sencilla y muy clara, muy equilibrada y evangélica. Casi sorprende este equilibrio en la vida espiritual de su tiempo. Mientras la gran parte de los maestros de vida espiritual insistían muchísimo en la mortificación corporal, el Beato Anselmo la consideraba muy secundaria. Continuamente recomendaba e insistía, a las religiosas que dirigía o le consultaban, en el sacrificio de someter la voluntad. A la Hna. María de San José, del convento de Sancti Spiritus de Valladolid, le escribía en febrero de 1923: «En lo que ha de poner especial empeño es en la mortificación interior y vencimiento de sí misma; así no hay peligro de ningún género y Dios queda sumamente complacido». Es el equilibrio de la Orden Agustina. Siguiendo la escuela agustina, su doctrina espiritual es cristocéntrica. Insiste muchísimo en la imitación de Cristo. En una toma de hábito en Valladolid exhorta a los nuevos

63. Amador del FUEYO, Ob. cit., p. 40. 
novicios: «Aprovechaos de la gracia singularísima que os concede el Señor con la vocación al estado religioso y corresponded a ella proponiendo y tomando por norma aquella sentencia del Kempis: "Summum igitur studium nostrum sit vita Iesuchristi meditari”.

Seguir y someterse a la voluntad de Dios era para él, y quería que fuera para los demás, un imperativo categórico. Dios sabe bien lo que hace o permite. Para esto se necesita una profunda humildad, virtud que cultivaba con amor y aconsejaba sin cesar. El primado de las virtudes se lo concedía a la caridad, para toda la vida cristiana, pero de una manera aún más vinculante para los miembros de la Orden Agustina, siguiendo el pensamiento de San Agustín. Recomendaba y enseñaba a vivir la presencia de Dios como uno de los medios más eficaces para conquistar la santidad. Crecer en la santidad fue la pasión de su vida. Le parecía una contradicción vivir en la vida religiosa y no asumir con decisión la opción de la santidad y los medios que conducen a ella.

Afirmaba que, además de la característica de la caridad, lo es para el agustino la ciencia. Por eso con frecuencia exhorta a hacer realidad en cada Hermano, en la Provincia, en la Orden, el binomio inseparable de «Virtud y Ciencia» y «Caridad y Ciencia». Todo eso necesita el apóstol, y el agustino ha de ser un apóstol incansable, un servidor humilde y entregado a la causa de la Iglesia.

\section{1) Conocedor de San Agustín.}

Amaba muchísimo a San Agustín y quería que todo agustino fuera un fiel discípulo de tal Padre. No puedo decir, sin embargo, que fuese un lector asiduo del Santo y menos un especialista. Lo cita con frecuencia; pero son frases de acarreo, tomadas de aquí y de allá, no directamente de las obras de Agustín. Ciertamente seguía un talante de vida verdaderamente agustina, hasta en amar y pedir ser corregido, y en ayudar a otros con su corrección. En el discurso al Capítulo Provincial de 1932 proclamó, contra ciertas tendencias de seguir a San Agustín en lo que a cada uno le gustara, que había que seguirlo globalmente, para que su doctrina y ejemplo sean provechosos.

"Oyese hablar con frecuencia de reagustinizarnos, y no seré yo quien levante la voz contra esa idea. ¿Acaso no es deber de los hijos imitar, reproduciéndolas, las virtudes excelsas de su Padre y de un tal Padre como el Santo y Doctor insigne que nos legó su nombre?... Pero, ¿cómo ha de llevarse a efecto? No fragmentariamente, limitándose a copiar este o el otro rasgo aislado, sino asimilándonos, apoderándonos de lo que en el original, en el prototipo, fue sustancia 
y principio y fundamento de sus admirables empresas: la piedad sólida e instruida, que ad omnia utilis est promissionem habens vitae quae nunc est et futurae $(\operatorname{Tim} 4,8) »$.

La perseverancia con sus ovejas, los fieles de Teruel, parece un calco de cuanto San Agustín enseñaba a Honorato, Obispo, que habían de hacer los Obispos en casos semejantes ${ }^{64}$. Nadie ha afirmado que en reafirmar su criterio y actuación se hubiese basado en la doctrina de San Agustín. Fuera como fuera, se asemejó a su Padre espiritual en la interpretación del Evangelio del Buen Pastor. Por eso el P. Lope Cilleruelo asoció a la carta de San Agustín a Honorato la noble actuación del Beato Polanco:

"Al poner punto final en una frase tan solemne, no puedo menos de recordar al Obispo de Teruel, mi venerado Superior durante ocho años de la carrera eclesiástica, martirizado por los rojos al fin de nuestra guerra de liberación, felicitándome de que aún quedan en el mundo espíritus heroicamente agustinianos. Porque el Sr. Obispo, consciente de su deber y de su riesgo, dio la vida como el buen Jesús por sus ovejas» ${ }^{65}$.

\section{2) El Beato Polanco y la guerra.}

Hacía varios años que el Beato Polanco veía España en una situación catastrófica, sobre todo bajo el aspecto socio-político y religioso. Se palpa en sus cartas, aunque pone toda su esperanza en Dios. En la citada Circular a la Provincia en 1932, al ser elegido Prior Provincial, se vislumbra su preocupación por las fuertes circunstancias adversas en España y en otras partes.

«La tormenta de fuera -afirmaba- amaga y arrecia y extiende el radio de asolamiento sin vislumbrarse en el horizonte indicios de próxima calma» ${ }^{66}$.

Cada vez fue viendo el horizonte más cargado de tormenta. Espera en Dios, cree que Dios dará el triunfo a los que considera defensores de la justicia y de la paz. Pero sabe que no basta la oración, que ha de ir acompañada de la acción. De ahí que exhorte a los católicos a votar en favor de la derecha, porque la izquierda persigue a la Iglesia, trastorna el orden de la justicia...

64. S. AGUSTÍN, Carta 228, BAC, vol. 11b, Madrid 1972, pp. 332-344. 500 .

65. Lope CILleruelo, OSA, El monacato de San Agustín y su Regla, Valladolid 1947, p.

66. Anselmo POLANCO, Circular, p. 8. 
En la Circular sobre las próximas elecciones, fechada en Teruel el 31 de enero de 1936, ve ya a España enfrentada en dos bandos:

"Luchan de un lado -afirma- los defensores de la religión, de la propiedad y de la familia; del otro los representantes y voceros de la impiedad, del marxismo y del amor libre. Son las dos ciudades enemigas de que habla San Agustín» ${ }^{67}$.

Como se ve, sus ideas eran las de la Iglesia del tiempo. Propone como uno de los puntos fundamentales de error del enemigo el ir contra la propiedad, sin más. Podría haber matizado un poco el tema siguiendo el concepto que San Agustín tenía de la propiedad ${ }^{68}$. Muy probablemente ignoraba el pensamiento de San Agustín bajo este aspecto.

Se llegó a convencer de que la paz no sería posible sin la intervención del ejército nacional. De ahí que saludara al ejército nacional como el salvador de España. Con todo, no quería la guerra, quería y buscaba la paz. Predicaba el amor, el perdón, la reconciliación. No quería que se hablara de los de la otra parte de España como de enemigos, sino de hermanos equivocados. Con San Agustín afirmaba que había que odiar el pecado, pero amar al pecador.

En la Exhortación pastoral, fechada en Teruel, 14 de marzo de 1937, se muestra seguro de que la guerra, aunque aún no acabada, ya está prácticamente ganada por el ejército nacional ${ }^{69}$. En sus escritos da la impresión de no conocer los desmanes que algunos realizaban en la parte nacional. Dado su amor a la verdad y a la justicia, los hubiera denunciado.

Balbino RANO, OSA

Institutum Patristicum Augustinianum

Roma

67. En BOEDTA. 77 (1936), p. 27.

68. Cf. SAN AGUSTÍN, Comentarios a los Salmos, 131, 5-6; Tratados sobre el Evangelio de San Juan, 6, 25.

69. BOEDTA. 77 (1937), pp. 255-266. 